\title{
MODELLING AND SIMULATING THE DYNAMICS OF THE EUROPEAN DEMAND FOR BIO-BASED PLASTICS
}

\author{
Horvat, D.; Wydra, S. \& Lerch, C. M. \\ Fraunhofer Institute for Systems and Innovation Research ISI, Breslauer Str. 48, 76139 Karlsruhe, \\ Germany \\ E-Mail: djerdj.horvat@isi.fraunhofer.de, sven.wydra@isi.fraunhofer.de, \\ christian.lerch@isi.fraunhofer.de
}

\begin{abstract}
Bio-based plastics are currently hardly competitive on the European market mainly due to their high production costs compared to fossil-based alternatives. A major issue in this context is the interplay between decreasing production costs and changing framework conditions and its effect on the competitiveness of bio-based plastics. In order to examine this, we developed a System Dynamics model that we use for simulations based on various assumptions defined in a high-level expert workshop. Our results show a positive influence on the market price and hence on the demand for biobased plastics of establishing new capacities and adopting new production technologies. Despite this, bio-based plastics will not achieve cost competitiveness in the next 15-year period if framework conditions with regard to the oil price remain unchanged and if no new policy incentives are introduced such as tax exemptions and subsidies for new technologies. This negative trend is further enhanced later on by rising feedstock prices on the biomass market.

(Received in December 2017, accepted in June 2018. This paper was with the authors 2 months for 2 revisions.)
\end{abstract}

Key Words: System Dynamics, Bio-Based Plastics, Scaling and Learning Effects, Feedstock Price, Price Competition

\section{INTRODUCTION}

Bio-based plastics (bio-based polymers) are an important segment of the bio-economy. On the one hand, the term bio-based plastic relates to the use of a specific raw material (biomass instead of fossil fuels). On the other hand, it refers to production methods (biotechnology instead of chemical synthesis) or to bio-degradability [1-3]. In this paper, we use the term for biotechnology-produced plastics based on biomass.

Bio-based plastics represent an important value chain in the bio-economy, comprising potential high-volume products in mass markets as well as specialized products with new functionalities in certain niches. There are numerous ways to apply bio-based plastics (e.g. packaging, textiles, consumer goods, agriculture \& horticulture, automotive \& transport). Moreover, they contribute to mitigating climate change by lowering $\mathrm{CO}_{2}$ emissions $[4,5]$.

Bio-based plastics sell on business-to-business but also business-to-consumer markets, which are associated with the bio economy and thus have a signalling function for other biobased product developments. However, bioplastic innovation and market diffusion are influenced by a wide range of interrelated factors and commercialization has not yet reached its earlier expectations [6]. Currently, a key obstacle for most bio-based products is that the costs of using them are considerably higher than the fossil-based alternatives [e.g. 7]. Although notable technological progress has been achieved $[3,8,9]$, the gap has not yet been closed [9]. Indeed, the falling oil price has had a negative effect on the cost competitiveness of bio-based plastics because this results in cheaper fossil-based plastics on the market.

Over the past 10 years, several policy instruments have been proposed to enhance the competitiveness of bio-based plastics, since their diffusion and potentially positive socioeconomic impacts as well as their potential to reduce conventional plastic waste [10] are 
being hampered by lock-in effects related to conventional plastics [1, 2, 11]. Among other things, bans on fossil-based plastics, exemption from value-added tax, subsidies for commercial plants, standardization and labelling have been discussed [11]. These suggestions may improve the competitiveness of bio-based plastics on the market in the long term.

It is well known that increasing demand for bio-based plastics will result in a higher demand for biomass feedstock and supply bottlenecks so that biomass producers can raise feedstock prices on the market. This implies an increased market price for bio-based plastics due to higher production costs [12-14]. However, studies have also demonstrated that production scale size and technological progress can reduce the market price of bio-based plastics by lowering production costs [15-16]. We also know from the literature that policy incentives in the form of direct and indirect subsidies can reinforce this effect [2]. However, there is no detailed information available about the interlinked effects of these on bio-based plastics' price competitiveness on the market or how this is affected by changing oil prices as the basis for fossil-based plastics (alternative products on the market).

There are some qualitative scenarios available for bio-based plastics that contain key drivers, but they do not assess the dynamics of development and provide only a qualitative rating of how the factors interrelate [6, 17]. In addition, bio-based plastics appear in quantitative modelling approaches for bio-based products [18]. However, these simulations are embedded in general scenarios for bio-based products that focus on only limited number of factors, with technological progress in production as the exogenous factor. Moreover, they do not feature specific economic results and dynamics for bio-based plastics as well as their interactive effects to specific policies. However, this interplay gives valuable insights into the system and hence for creating policies, e.g. [19].

With this article, we contribute to the literature by addressing the research question:

How will the interaction between changing production costs and framework conditions influence the price competitiveness and thus the demand for bio-based plastics on the market in the next 10 years?

In order to answer this question, we used a methodological approach combining scenario elaboration and modelling simulation. To formulate hypotheses about the dynamics, or in other words to define possible pathways for bio-based plastics in Europe in the next 10 years, we first conducted a scenario workshop with experts from research and industry across Europe. In this workshop, we defined the time horizon, the current situation for technology, business and policy as well as assessed the key variables and interactions between them for our model. Three alternative scenarios resulted from combining different possible future developments for each key factor. We then constructed a qualitative "causal loop" diagram [18] that represents the structure and dynamic behaviour of the bio-based plastics value chain and formulated our simulation model, the so-called "stock and flow" diagram [18]. We used the relevant market data for the mathematical models as well as scaling and learning rates taken from the current literature [3, 5, 9, 14-17]. We integrated only those segments into our model, where bio-based plastics compete directly as a drop-in for certain applications and can compete directly with fossil-based plastics. Finally, we used our model to simulate the narratively elaborated scenarios for bio-based plastics from the workshop with a time frame of 15 years.

\section{METHODOLOGY}

System Dynamics (SD) is a modelling methodology that makes it possible to analyse the dynamics of socio-economic systems and simulate their long-term trends [20, 21]. Due to its configuration, SD can represent a holistic picture of complex system processes in one model by using differential equations describing all the relevant material, financial, and information 
flows [22]. The SD approach is suitable for researching dynamic problems from a wide range of fields, e.g. business, social, economic, biological and ecological [23]. This method also provides reliable assessments despite the complex effects due to coupling structures, time delays, and aggregations as well as general cases of non-linearity. It can overcome the natural tendency towards linear thinking [22] and effectively analyse the dynamic behaviour of a system and its individual parameters using continuous computer-based simulation. This enhances the understanding of the effects of past decisions and makes the interaction of individual variables more transparent $[20,21]$. SD is thus a scientific method that enables the ex-ante examination and evaluation of the long-term impacts of decisions on a system as well as the existing interactions within the system under different environmental dynamics [24].

We used SD for this study because of the following features:

- it allows the relationships between key factors in the value chain of bio-based plastics to be formalised,

- it allows explorative simulations under different frame conditions and

- it facilitates policy recommendations based on quantified, mathematical forecasts.

The paper is organised as follows: First, based on the literature and the results of a scenario workshop, we present the main variable interactions. We also use these interactions to conceptualise the model, i.e. construct a causal loop diagram. This conceptual model then serves as a basis for our (mathematical) simulation model, i.e. a stock and flow diagram. We present the results of the model's simulation runs used to analyse the influence of specific factors and to gain insights into the system's behaviour. Finally, we draw several conclusions from these findings.

\section{MODEL CONCEPTUALISATION}

Our model has a structure comprising three subsystems (see Fig. 1):

Subsystem 1 (Production): Effects of establishing new capacities and adopting new technologies in production on production costs and thus the market price for bio-based plastics.

Subsystem 2 (Feedstock): Effects of a changing feedstock price on production costs and thus the market price for bio-based plastics.

Subsystem 3 (Market): Effects of price competition on the demand for bio-based plastics.

\subsection{Conceptual model - causal loop diagram}

We base our first subsystem (Production) on the assumption in the production management literature that establishing new capacities as well as adopting new technologies and process improvements in manufacturing reduce the process costs for producers [15, 25]. These cost reduction effects, which result from modernizing manufacturing processes and increasing production scale size, are known as scaling and learning effects. In the context of bio-based products, most of the current studies document considerable market price reductions due to these effects that may well result in the prices for bio-based and fossil-based plastics converging in 15 to 20 years $[3,5,7,9,15,16,18,25]$. We assume a positive influence of learning and scaling effects on the demand for bio-based plastics due to the expected increase in customer awareness and thus higher price elasticity on the market. Therefore, we establish a reinforcing feedback loop within the first subsystem (see Subsystem 1 in Fig. 1) [19, 21].

The increase in the demand for bio-based plastics (as a finished product on the market) influences the feedstock price on the market at the same time as the process costs. The rising demand for bio-based plastics implies a higher demand for feedstock resulting in biomass 
supply bottlenecks and feedstock producers raising their prices on the market. This will have negative effects on the demand for bio-based plastics - due to increased production costs (see also [12-14]). This subsystem therefore features a balancing feedback loop (see Subsystem 2 - Feedstock in Fig. 1).

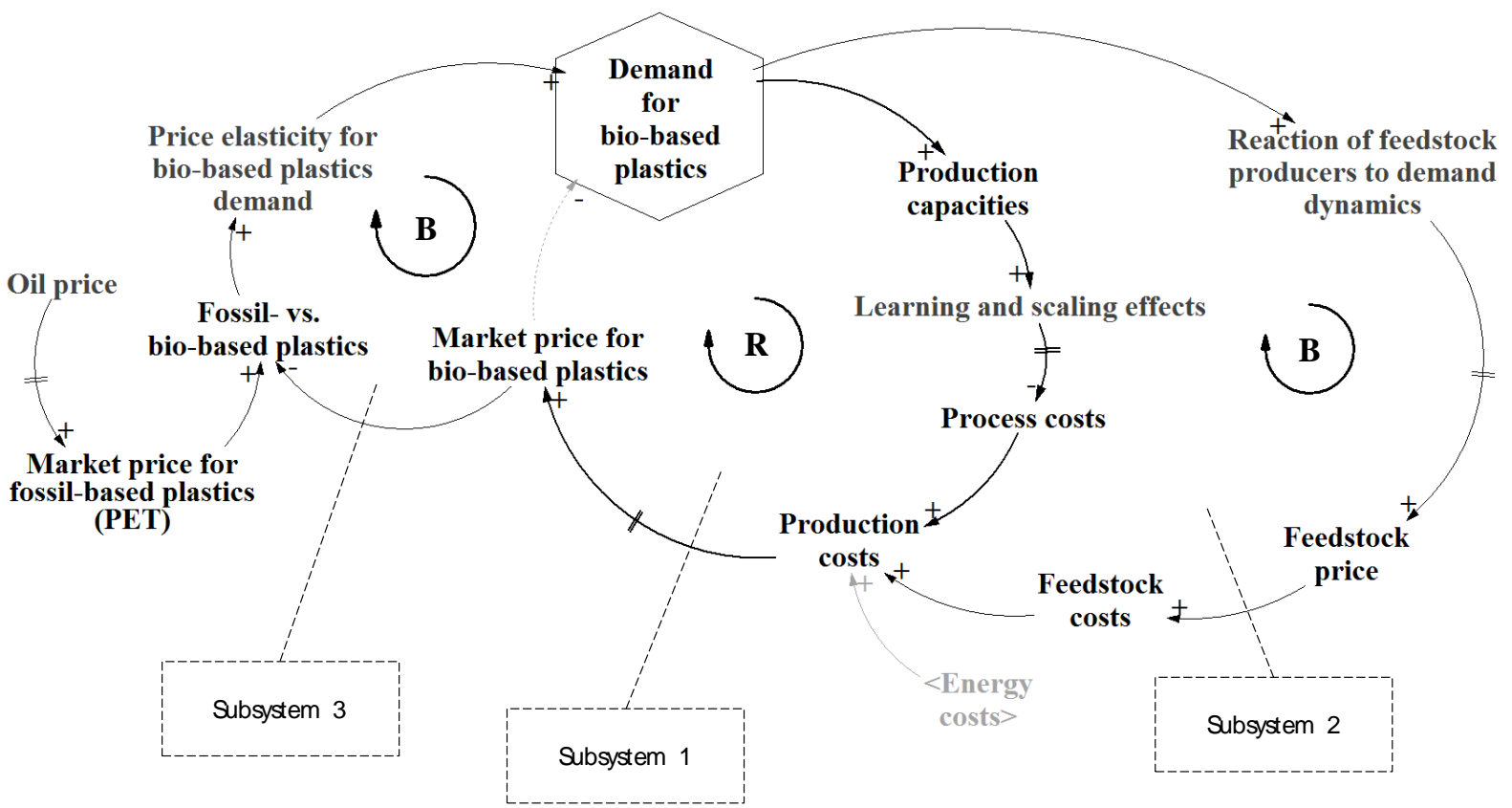

Figure 1: Conceptual model - causal loop diagram.

Based on the inputs from the expert workshop, we simplified our model by limiting the production costs to three key components for price generation: feedstock costs, process costs and energy costs. Similarly, we treat production costs as an individual variable of the market price for bio-based plastics, and disregard the costs for R\&D, marketing, logistic costs etc.

In terms of the current market situation, bio-based plastics compete mainly with fossilbased plastics as their non-bio-based alternative $[1,7,11,26]$. According to numerous studies $[6,11]$, price competitiveness is very important for bio-based plastics, at least on mass markets. There are some indications of a moderate willingness-to-pay more for bio-based plastics, because of their green image and partly superior sustainability performance, but there is hardly any evidence for a high so-called green premium for many types of bio-based plastics [27]. Hence, bio-based plastics have to be price competitive with their fossil-based counterparts. Production efficiency and the relative feedstock prices are therefore very relevant for bio-based plastics. The latter are strongly dependent on the oil price. A high oil price increases the prices for fossil-based plastics, and therefore has a positive effect on the demand for bio-based plastics $[5,9,11]$.

This interrelatedness between fossil-based and bio-based plastics means the price elasticity of the demand for bio-based plastics acts in conjunction with the price of fossilbased plastics. The cheaper bio-based plastics are in comparison to fossil-based plastics, the higher demand will be. On the other hand, demand will be lower if bio-based plastics are more expensive than fossil-based ones on the market. It results in a balancing feedback loop [28] (see Subsystem 3 - Market in Fig. 1).

Here, the assumed price elasticity of demand is of key importance. There are no historical data available to estimate the price elasticity of bio-based plastics, so we rely on the intensive analysis by Dornburg et al., who conclude that 0.3 is a reasonable value [29]. For the case that bio-based plastics are cheaper than fossil-based ones, we assume this value increases to 0.6 as this addresses price-sensitive market segments. 


\subsection{Simulation model - stock and flow diagram}

We construct our simulation model or, in System Dynamics' terms, our "stock and flow" diagram in accordance with our causal loop diagram, current literature and inputs from the expert workshops. It is based on stocks, which explains the accumulations or integrals of (inand out-) flows (see Fig. 2). We used the VENSIM software platform to model the complex system structure.

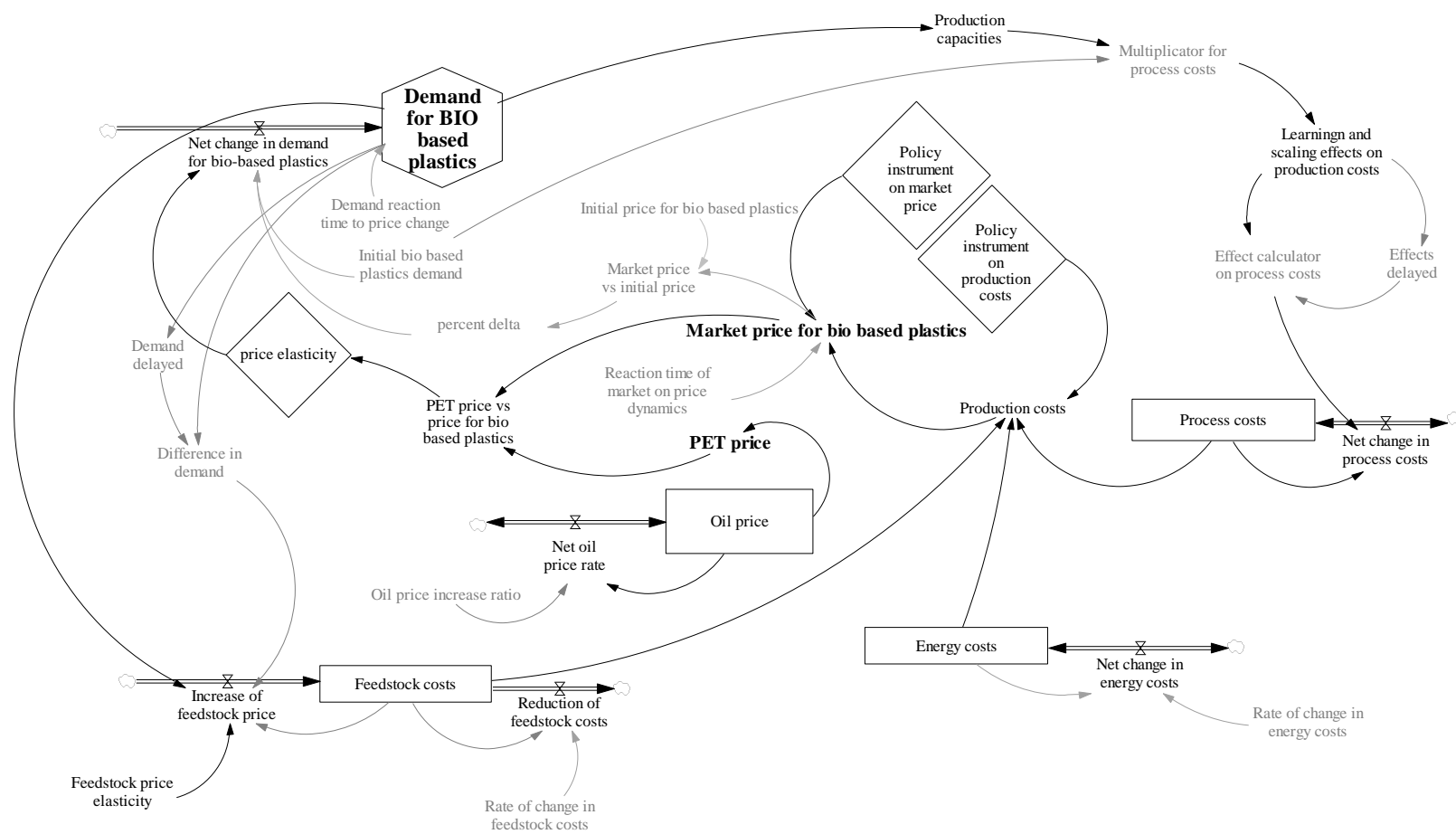

Figure 2: Simulation model - stock and flow diagram.

To simplify the model, we assume that the monthly production capacities match the monthly demand for bio-based plastics on the market:

where:

$$
D_{\text {overall }}(t)=P R_{\text {monthly }}(t)
$$

$D_{\text {overall }}-$ Monthly demand [million $\mathrm{kg} /$ month]

$P R_{\text {monthly }}-$ Monthly production capacity [million $\mathrm{kg} / \mathrm{month}$ ]

As explained in our conceptual model, we calculate the production costs of bio-based plastics as a simple sum of the process, feedstock and energy costs. Following Subsystem 1 of our conceptual model, process costs depend on the monthly production capacities as well as the technologies used in manufacturing. Monthly process costs are calculated by:

where:

$$
C_{\text {process }}(t)=C_{\text {process }}\left(t_{0}\right)+\int_{t_{0}}^{t_{180}}\left(C_{\text {process }}(t) \cdot s(t)\right) d t
$$

$$
\begin{array}{ll}
C_{\text {process }} & - \text { Process costs [EUR } / \mathrm{kg}] \\
s & - \text { Learning and scaling effects [Dmnl] }
\end{array}
$$

Data for cost structures and prices for bio-based and fossil-based products have been taken from $[9,16,18]$. As a bio-based reference, we use cost data of around 2 EUR/kg for PLA (Polylactic acid) - a transparent plastic produced from corn or dextrose, while the price for our fossil-based reference PET (Polyethylene terephthalate) is estimated at around 1 EUR/kg in 2015 [5]. Based on the literature and results of the expert workshop, we calculated 
the influence of production capacities on process costs by incorporating scaling and learning effects that range from $2 \%$ to $0.5 \%$. This corresponds to multiplying the production capacities by 1 to 4 compared to the start demand. We include a 3-month delay to consider the time lag occurring after a scale and/or learning effect until the price reduction is felt.

Following the Subsystem 2 of our conceptual model, we calculate the feedstock costs for producing bio-based plastics based on the change in feedstock price on the market determined by the feedstock producers; see Eq. (3) [13]. For the initial value, we use $0.768 \mathrm{EUR} / \mathrm{kg}$.

We calculate a feedstock price elasticity of 0.1 (see Eq. (4)) to model the increase in feedstock costs, i.e. the feedstock price increase due to the reaction of feedstock producers to demand fluctuation for end products (bio-based plastics) on the market (see Subsystem 2 in Fig. 1). To calculate the fluctuation in demand on the market, we compare the demand for bio-based plastics using time steps of 6 months; see Eq. (6). We assume that the feedstock producers will adapt their prices to market fluctuations once a year, so the price increase is spread over 12 months.

We used a constant annual rate of change of $0.8 \%$ to model the decrease in feedstock costs; see Eq. (5).

where:

$$
\begin{gathered}
C_{\text {feedstock }}(t)=C_{\text {feedstock }}\left(t_{0}\right)+\int_{\mathrm{t}_{0}}^{\mathrm{t}_{180}}\left(p^{+}{ }_{\text {feedstock }}(t)-p_{\text {feedstock }}^{-}(t)\right) d t \\
p_{\text {feedstock }}^{+}(t)=\frac{\left(C_{\text {feedstock }}(t) \times D_{\Delta}(t) \times e_{\mathrm{p}}^{\text {feedstock }}\right)}{12} \\
p_{\text {feedstock }}^{-}(t)=C_{\text {feedstock }}(t) \cdot r \\
D_{\Delta}(t)=\frac{\left(D_{\text {overall }}(t)\right)}{\left(D_{\text {overall }}(t-6)\right)}-1
\end{gathered}
$$

$$
\begin{array}{ll}
C_{\text {feedstock }} & - \text { Feedstock costs [EUR/kg] } \\
p^{+}{ }_{\text {feedstock }}(t) & - \text { Increase of feedstock price [Dmnl] } \\
p^{-} \text {feedstock }(t) & - \text { Reduction of feedstock price [Dmnl] } \\
e_{\mathrm{p}}{ }_{\text {feedstock }} & - \text { Feedstock price elasticity [Dmnl] } \\
D_{\Delta}(t) & - \text { Difference in demand [Dmnl] } \\
r & - \text { Rate of change in feedstock costs [Dmnl] }
\end{array}
$$

In accordance with Subsystem 3, we model the monthly demand for bio-based plastics using the variable price elasticity, which alters in conjunction with the price of fossil-based plastics on the market (see Table I).

$$
\begin{gathered}
D_{\text {overall }}(t)=D\left(t_{0}\right)+\int_{\mathrm{t}_{0}}^{\mathrm{t}_{180}}\left(D\left(t_{0}\right) \cdot p_{\Delta}(t) \cdot e_{\mathrm{p}}^{\text {demand }}\right) d t \\
p_{\Delta}(t)=1-\frac{p_{\text {real }}(t)}{p\left(t_{0}\right)}
\end{gathered}
$$

where:

$$
\begin{array}{ll}
D_{\text {overall }} & - \text { Monthly demand [million } \mathrm{kg} / \text { month] } \\
D\left(t_{0}\right) & - \text { Initial demand [million } \mathrm{kg} / \mathrm{t}_{0} \text { ] } \\
p_{\Delta} & - \text { Difference between market price and initial price [Dmnl] } \\
e_{\mathrm{p}} \text { demand } & - \text { Price elasticity [Dmnl] } \\
p_{\text {real }}(t) & - \text { (real) market price }[\mathrm{EUR} / \mathrm{kg}] \\
p\left(t_{0}\right) & - \text { Initial price [EUR/kg] }
\end{array}
$$

A delay of two months is integrated into the model to account for the time lag until customers react to price changes. 


\section{SCENARIOS}

Recently, there have been a number of attempts to combine narrative scenarios and quantitative modelling in order to derive a more comprehensive and more transparent future outlook [30-32]. In order to elaborate the possible pathways for bio-based plastics in Europe in the next 10-12 years, we conducted a scenario workshop as part of a research project for the EU. This took place on $8^{\text {th }}$ March 2017 in Frankfurt and was attended by 12 experts from research and industry across Europe. The guiding question for the workshop was what the value chain for bio-based plastics in Europe looks like in 2025-2030 from different perspectives: technological, business, societal and policy. The following steps were taken:

- Assessment of the factors and current situation for technology, business and policy based on the literature.

- Prioritization of the key factors and description of their alternative future developments along the value chain.

- Elaboration of three alternative scenarios by combining different possible future developments for each key factor.

These steps resulted in three distinct future scenarios for bio-based plastics containing mostly qualitative information combined with a few quantitative characteristics, such as the oil price. The qualitative information (such as the existence of demand-side policies for biobased plastics) was then turned into quantitative data based on a literature review. While detailing the full narrative of the scenarios is beyond the scope of this paper, the key characteristics for the modelling and simulation approach are shown below (see also Table I):

1. Baseline scenario: Incremental advances in technology and market awareness and no policy changes.

2. High oil price scenario: A steady rise in the price of oil up to 127 US dollars per barrel in 2030 [30] and no significant policy measures.

3. De-risking scenario: Substantial policy support for commercial activities, tax exemptions to decrease prices and higher consumer demand.

Table I: Assumptions for scenarios.

\begin{tabular}{|l|c|c|c|c|c|}
\hline \multirow{2}{*}{ Scenario } & \multirow{2}{*}{$\begin{array}{c}\text { Oil price } \\
\text { (US\$/bbl) }\end{array}$} & $\begin{array}{c}\text { Policy instrument } \\
\text { on market price } \\
(\%)\end{array}$ & $\begin{array}{c}\text { Policy instrument } \\
\text { on production costs } \\
\text { (EUR/t) }\end{array}$ & $\begin{array}{c}\text { Bio-based plastics } \\
\text { more expansive } \\
\text { than fossil-based } \\
\text { alternatives }\end{array}$ & $\begin{array}{c}\text { Bio-based plastics } \\
\text { cheaper than fossil- } \\
\text { based alternatives }\end{array}$ \\
\hline $\begin{array}{l}\text { Baseline } \\
\text { scenario }\end{array}$ & $\sim 100$ & 0 & 0 & 0.3 & 0.6 \\
\hline $\begin{array}{l}\text { High oil price } \\
\text { scenario }\end{array}$ & $\sim 125$ & 0 & 0 & 0.3 & 0.6 \\
\hline $\begin{array}{l}\text { De-risking } \\
\text { scenario }\end{array}$ & $\sim 100$ & 10 & 100 & 0.4 & 0.7 \\
\hline
\end{tabular}

\section{RESULTS}

The structure of our SD model was verified by validation tests and was then ready for use. Various simulation runs and tests were done in order to gain a deeper understanding of the system's behaviour.

Fig. 3 shows the results of three simulation runs. The graph plots the demand for biobased plastics in the three different scenarios and shows the effect of a changing oil price, supportive policy measures and price elasticity. 


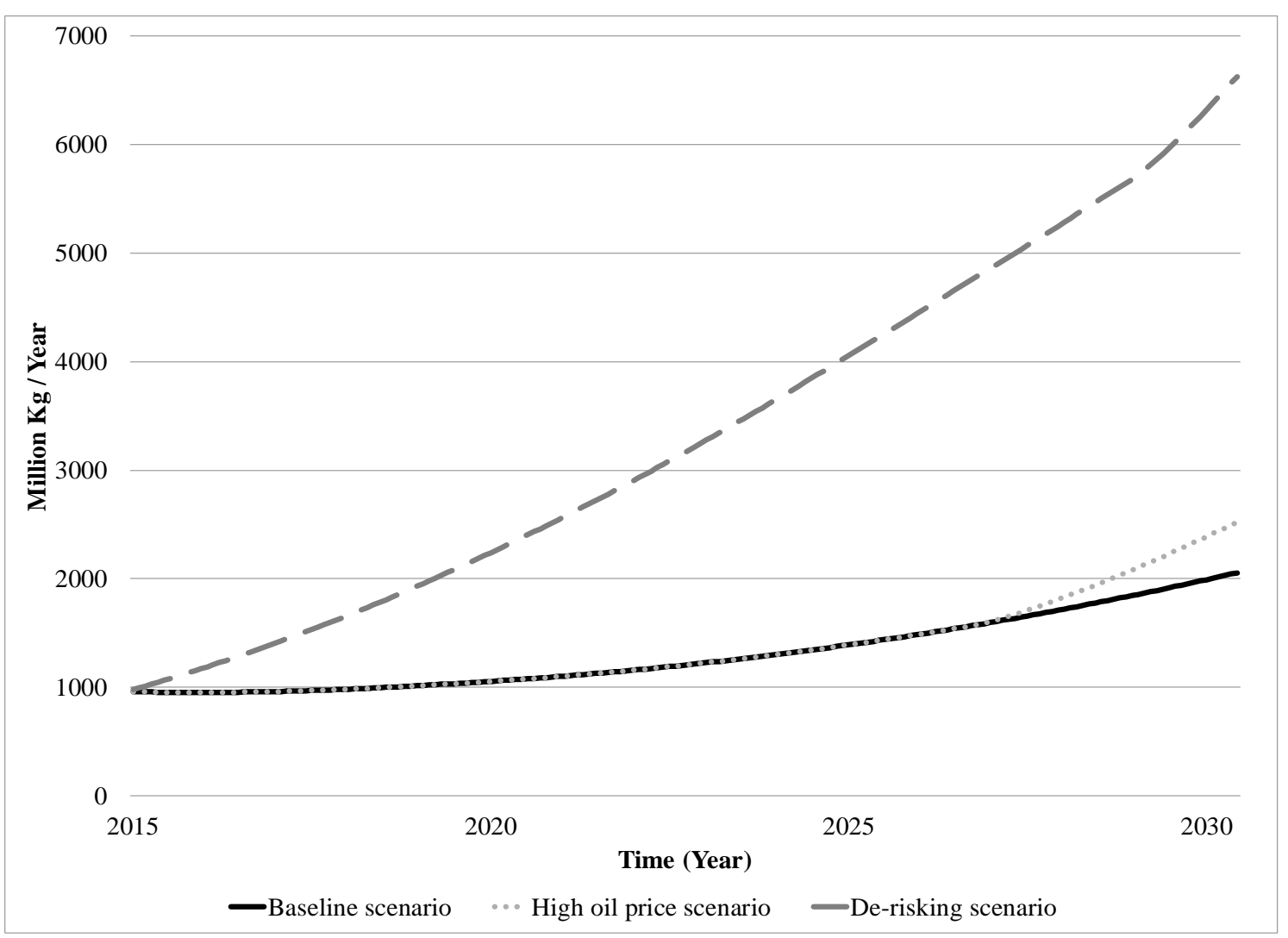

Figure 3: Demand for bio-based plastics influenced by low and high oil prices and by supportive policy measures.

The solid black line represents the baseline scenario (see Fig. 3), which assumes a stable and moderate oil price and consequently lower market prices for fossil-based alternatives over the whole time horizon (see Fig. 4). This scenario does not include any policy incentives favouring bio-based plastics. The slight drop in production costs, and thus in the market price for bio-based plastics, is a consequence of learning effects from adopting new manufacturing technologies. There is also a slight drop in feedstock prices on the market. Due to the insignificant rise in demand for bio-based plastics, farmers are not likely to raise feedstock prices, but reduce them slightly. The overall result is that bio-based plastics will not become price competitive on the market (see Fig. 4).

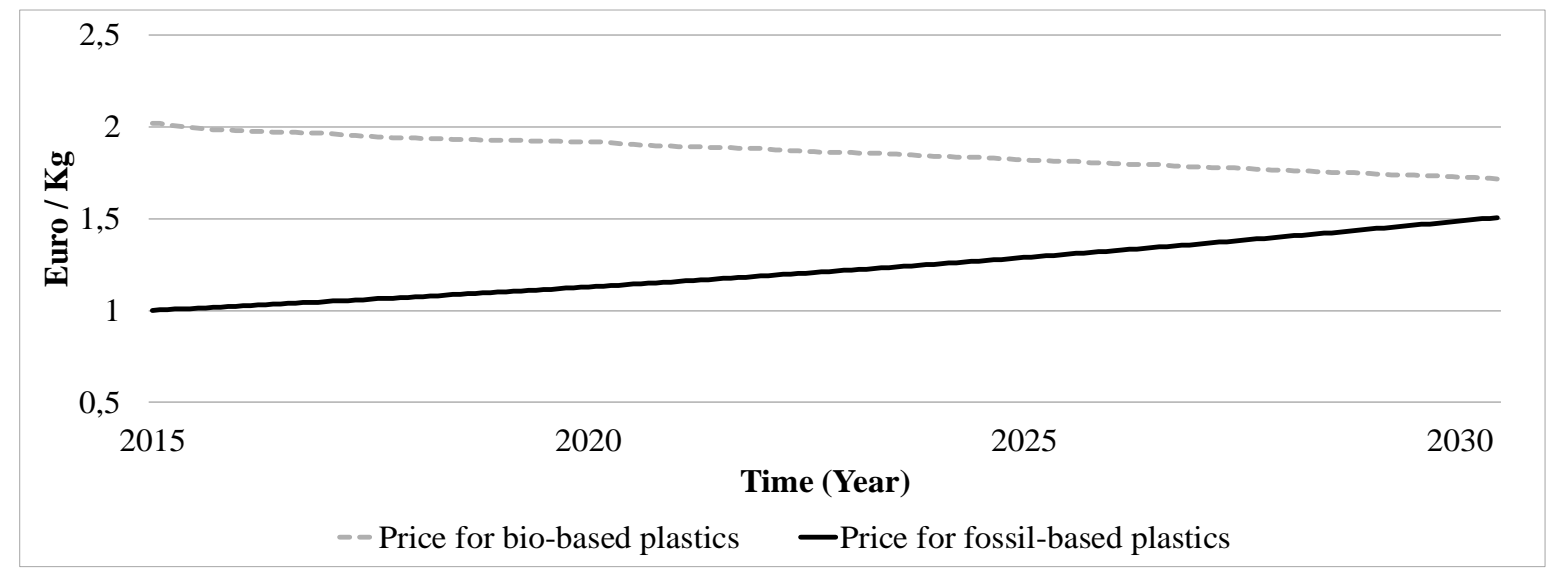

Figure 4: Price competitiveness between bio-based and fossil-based plastics - Baseline scenario.

The dotted grey line in Fig. 3 represents the high oil price scenario, which assumes a continuous increase in the oil price to $127 \mathrm{US} \$ / \mathrm{bbl}$ in 2030, e.g. [9]. All other assumptions are 
the same as the baseline scenario in order to single out the impacts of an increased oil price on the demand for bio-based plastics. Due to the rising prices for fossil-based alternatives, biobased plastics are expected to be cost competitive after 2025 (see Fig. 5). As soon as they are competitive on the market, demand will start to increase significantly (see Fig. 3). However, there will only be a moderate increase in the demand for bio-based plastics in the period considered.

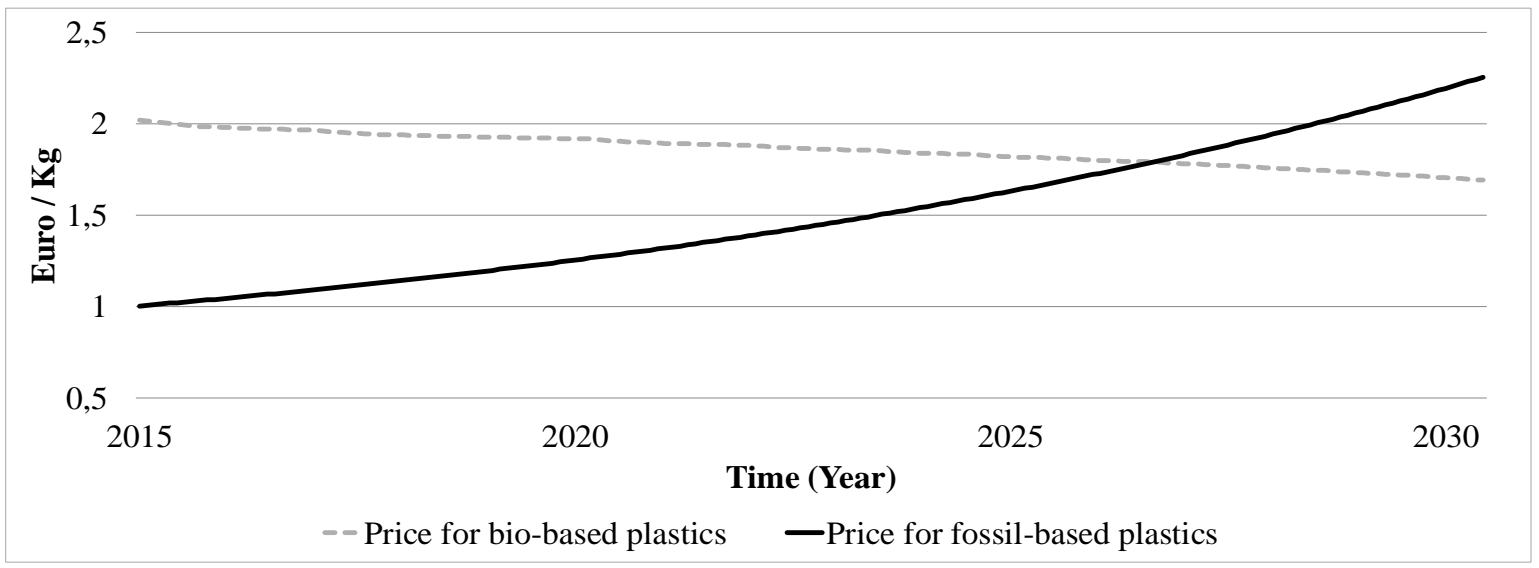

Figure 5: Price competitiveness of bio-based and fossil-based plastics - High oil price scenario.

The dashed grey line in Fig. 3 depicts the de-risking scenario, which assumes a low oil price and includes policy incentives that favour bio-based plastics. Furthermore, compared to the other two scenarios, we assume a higher response of consumers by modelling higher price elasticity when calculating the demand for bio-based plastics. In spite of the low oil price, the demand for bio-based plastics grows much more strongly than in the other scenarios (see Fig. 3). This growth results, on the one hand, from higher production scales and technological process improvements. On the other hand, policy incentives, such as tax exemptions (with price lowering effects) and subsidies for new technologies (with the effect of lowering process costs) $[1,2,26]$ enhance the competitiveness of bio-based plastics in comparison to fossil-based ones (see Fig. 6). These incentives even neutralise the negative effects of rising feedstock prices on the market.

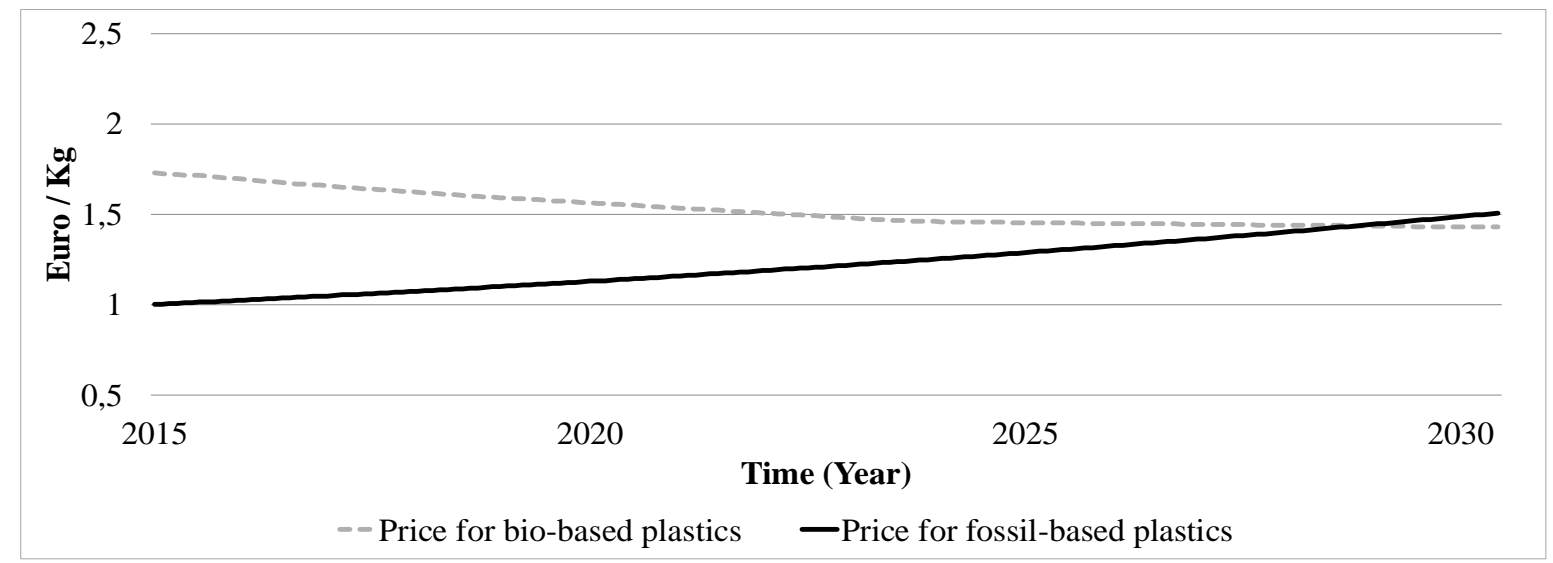

Figure 6: Price competition between bio-based and fossil-based plastics - De-risking scenario.

\section{CONCLUSIONS}

In this paper, we analyse the influence on the competitiveness of bio-based plastics on the European market of the interaction between fluctuating production costs (resulting from 
changes in the feedstock price on the market as well as from scaling and learning effects in production) and changing framework conditions (resulting from policy incentives and oil price dynamics). We used a System Dynamics model for the analysis, which represents the structure of the bio-based plastics value chain in a simplified way. Based on assumptions defined in an expert workshop, we applied this model in three simulation runs to obtain insights into the system's dynamic behaviour.

Our simulation runs show that establishing new capacities and adopting new technologies in production have the effect of decreasing production costs, and thus the market price for bio-based plastics. Despite these positive effects, bio-based plastics are currently still considerably more expensive than fossil-based ones and only applied in niche markets. Any rise in feedstock prices on the biomass market will have a further negative influence on this trend. Therefore, a significant market impulse is needed to accelerate the positive feedback loop described in the model. A substantial, steady increase in the oil price will not be sufficient for this, as it would take a long time to close the cost gap between bio-based and fossil-based products. Instead, policy instruments are required that trigger an increase in the oil price as the principal factor of influence on the prices of fossil-based plastics, and policy incentives that favour bio-plastic producers such as tax exemptions and subsidies for new technologies. These policies will be a key factor for further increasing the demand for biobased plastics.

This analysis focuses solely on the economic impact of potential policy instruments, and does not claim to be a comprehensive analysis of whether policy interventions are justifiable from a market failure or system of innovations perspective. Here, the debate centres on the sustainability performance of bio-based plastics. The related indicators are not included in this modelling process, but should be part of any further analysis.

\section{ACKNOWLEDGEMENT}

This study is based on the results of the project "Priorities for Addressing Opportunities and Gaps of Industrial Biotechnology for an efficient use of funding resources - PROGRESS" funded by the European Union's Horizon 2020 research and innovation programme under grant agreement No. 723687. As such, its online access is open and free of charge for any user. To prove the quality of the model, we presented a simplified version at the $17^{\text {th }}$ Scientific Conference on Industrial Systems. Based on the feedback of experts, we extended our model by including additional factors and a new sub-system thereby improving its validity and stability. Based on the same assumptions defined in the expert workshop, we then ran new simulations. In this paper, we present the adjusted version of the model and the results of our three simulations.

\section{REFERENCES}

[1] Kaeb, H. (2009). Bioplastics: Technology, Markets, Policies, $4^{\text {th }}$ European Bioplastics Conference, Berlin

[2] Philp, J. C. (2014). Biobased chemicals and bioplastics: Finding the right policy balance, Industrial Biotechnology, Vol. 10, No. 6, 379-383, doi:10.1089/ind.2014.1540

[3] Shen, L.; Haufe, J.; Patel, M. K. (2009). Product overview and market projection of emerging bio-based plastics: PRO-BIP 2009, Final Report, Copernicus Institute for Sustainable Development and Innovation, Utrecht University, Utrecht

[4] Mapleston, P. (2006). Environmentally degrading: Bioplastics in Europe (part 2), Plastics Engineering Europe, Spring 2006, 24-29

[5] European Bioplastics e.V. (2017). Bioplastics market data, from http://www.europeanbioplastics.org/market/, accessed on 4-6-2017

[6] Lettner, M.; Schöggl, J.-P.; Stern, T. (2017). Factors influencing the market diffusion of biobased plastics: Results of four comparative scenario analyses, Journal of Cleaner Production, Vol. 157, 289-298, doi:10.1016/j.jclepro.2017.04.077 
[7] Iles, A.; Martin, A. N. (2013). Expanding bioplastics production: Sustainable business innovation in the chemical industry, Journal of Cleaner Production, Vol. 45, 38-49, doi:10.1016/ j.jclepro.2012.05.008

[8] Bastioli, C. (Ed.). (2005). Handbook of Biodegradable Polymers, Rapra Technology Limited, Shawbury

[9] van den Oever, M.; Molenveld, K.; van der Zee, M.; Bos, H. (2017). Bio-based and biodegradable plastics - Facts and figures: focus on food packaging in the Netherlands, Report Nr. 1722, Wageningen Food \& Biobased Research, Wageningen

[10] Žmak, I.; Hartmann, C. (2017). Current state of the plastic waste recycling system in the European Union and in Germany, Technical Journal, Vol. 11, No. 3, 138-142

[11] BIO-TIC (2015). Overcoming hurdles for innovation in industrial biotechnology - Market Roadmap, from http://www.industrialbiotech-europe.eu/bio-tic/deliverables/, accessed on 18-52018

[12] Blumberga, A.; Bazbauers, G.; Davidsen, P. I.; Blumberga, D.; Gravelsins, A.; Prodanuks, T. (2018). System dynamics model of a biotechonomy, Journal of Cleaner Production, Vol. 172, 4018-4032, doi:10.1016/j.jclepro.2017.03.132

[13] Stern, T.; Ledl, C.; Braun, M.; Hesser, F.; Schwarzbauer, P. (2015). Biorefineries' impacts on the Austrian forest sector: A system dynamics approach, Technological Forecasting and Social Change, Vol. 91, 311-326, doi:10.1016/j.techfore.2014.04.001

[14] Condon, N.; Klemick, H.; Wolverton, A. (2015). Impacts of ethanol policy on corn prices: A review and meta-analysis of recent evidence, Food Policy, Vol. 51, 63-73, doi:10.1016/j.foodpol.2014.12.007

[15] Daugaard, T.; Mutti, L. A.; Wright, M. M.; Brown, R. C.; Componation, P. (2015). Learning rates and their impacts on the optimal capacities and production costs of biorefineries, Biofuels, Bioproducts and Biorefining, Vol. 9, No. 1, 82-94, doi:10.1002/bbb.1513

[16] Wydra, S. (2009). Produktions-und Beschäftigungseffekte neuer Technologien: Am Beispiel der Biotechnologie, Peter Lang, Bern

[17] Schwark, F. (2009). Influence factors for scenario analysis for new environmental technologies the case for biopolymer technology, Journal of Cleaner Production, Vol. 17, No. 7, 644-652, doi: $10.1016 /$ j.jclepro.2008.11.017

[18] Tsiropoulos, I. (2016). Emerging bioeconomy: Assessing the implications of advanced bioenergy and biochemicals with bottom-up and top-down modelling approaches, Dissertation, Utrecht University, Utrecht

[19] Sterman, J. D. (2000). Business dynamics: Systems thinking and modeling for a complex world, McGraw-Hill Education Ltd, New York

[20] Forrester, J. W. (1968). Industrial dynamics - after the first decade, Management Science, Vol. 14, No. 7, 398-415, doi: $10.1287 / \mathrm{mnsc} .14 .7 .398$

[21] Milling, P. (1984). Leitmotive des System-Dynamics-Ansatzes, Wirtschaftswissenschaftliches Studium, Vol. 13, No. 10, 507-513

[22] Sterman, J. D. (2001). System dynamics modeling: Tools for learning in a complex world, California Management Review, Vol. 43, No. 4, 8-25, doi:10.2307/41166098

[23] Sandrock, J. (2006). System dynamics in der strategischen Planung: Zur Gestaltung von Geschäftsmodellen im E-Learning, Deutscher Universitätsverlag, Gabler Verlag, Springer Fachmedien, Wiesbaden

[24] Larsen, E. R.; Bunn, D. W. (1999). Deregulation in electricity: understanding strategic and regulatory risk, Journal of the Operational Research Society, Vol. 50, No. 4, 337-344, doi:10.1057/palgrave.jors.2600695

[25] Festel, G.; Würmseher, M.; Rammer, C. (2014). Scaling and learning effects of biofuels conversion technologies, Energy Technology, Vol. 2, No. 7, 612-617, doi:10.1002/ ente. 201400014

[26] McCormick, K.; Kautto, N. (2013). The bioeconomy in Europe: An overview, Sustainability, Vol. 5, No. 6, 2589-2608, doi:10.3390/su5062589

[27] Carus, M.; Partanen, A.; Dammer, L. (2016). Are there GreenPremium prices for bio-based plastics?, Bioforever paper 2016-11, 2 pages, Nova-Institut GmbH, Hürth 
[28] Lv, X.; Huang, J.-H.; Liu, H.-B. (2017). Optimal manufacturing/remanufacturing policies with fixed investment for the underdeveloped remanufacturing system, Technical Gazette, Vol. 24, No. 5, 1491-1499, doi:10.17559/TV-20170829170855

[29] Dornburg, V.; Faaij, A.; Patel, M.; Turkenburg, W. C. (2006). Economics and GHG emission reduction of a PLA bio-refinery system - Combining bottom-up analysis with price elasticity effects, Resources, Conservation and Recycling, Vol. 46, No. 4, 377-409, doi:10.1016/ j.resconrec.2005.08.006

[30] Bauer, N.; Calvin, K.; Emmerling, J.; Fricko, O.; Fujimori, S.; Hilaire, J.; Eom, J.; Krey, V.; Kriegler, E.; Mouratiadou, I.; de Boer, H. S.; van den Berg, M.; Carrara, S.; Daioglou, V.; Drouet, L.; Edmonds, J. E.; Gernaat, D.; Havlik, P.; Johnson, N.; Klein, D.; Kyle, P.; Marangoni, G.; Masui, T.; Pietzcker, R. C.; Strubegger, M.; Wise, M.; Riahi, K.; van Vuuren, D. P. (2017). Shared socio-economic pathways of the energy sector - quantifying the narratives, Global Environmental Change, Vol. 42, 316-330, doi:10.1016/j.gloenvcha.2016.07.006

[31] Houet, T.; Marchadier, C.; Bretagne, G.; Moine, M. P.; Aguejdad, R.; Viguie, V.; Bonhomme, M.; Lemonsu, A.; Avner, P.; Hidalgo, J.; Masson, V. (2016). Combining narratives and modelling approaches to simulate fine scale and long-term urban growth scenarios for climate adaptation, Environmental Modelling \& Software, Vol. 86, 1-13, doi:10.1016/j.envsoft.2016.09.010

[32] International Energy Agency (2016). World Energy Outlook 2016, from https://www.iea.org/newsroom/news/2016/november/world-energy-outlook-2016.html, accessed on 18-05-2018 